\title{
Educação Midiática e referenciais metodológicos para a elaboração de oficinas no ensino remoto
}

\author{
Media education and methodological references for the elaboration of \\ workshops in remote education
}

\section{Educación mediática y referencias metodológicas para el desarrollo de talleres en teleaprendizaje}

\author{
Rejane de Mattos Moreira \\ Universidade Federal Rural do Rio de Janeiro - RJ - Brasil \\ ORCID: https://orcid.org/0000-0002-5792-8358 \\ Endereço Currículo Lattes: http://lattes.cnpq.br/6954578111040986 \\ E-mail: rejanemmoreira@gmail.com \\ Ana Carla Ferreira Longo Moraes \\ Universidade Federal Rural do Rio de Janeiro - RJ - Brasil \\ ORCID: https://orcid.org/0000-0002-5363-7289 \\ Endereço Currículo Lattes: http://lattes.cnpq.br/8812655167341966 \\ E-mail: carlaanasc3292@gmail.com \\ Anny Gabrielle Fernandes Aragão \\ Universidade Federal Rural do Rio de Janeiro - RJ - Brasil \\ ORCID: https://orcid.org/0000-0002-9921-2999 \\ Endereço Currículo Lattes: http://lattes.cnpq.br/0547993954790676 \\ E-mail: agfa0011@gmail.com \\ Mylena Machado da Silva Pinto \\ Universidade Federal Rural do Rio de Janeiro - RJ - Brasil \\ ORCID: https://orcid.org/0000-0002-1976-0718 \\ Endereço Currículo Lattes: http://lattes.cnpq.br/3377300663803759 \\ E-mail: machadomylena6@gmail.com
}

\begin{abstract}
Resumo: O artigo discute a elaboração de oficinas de leituras críticas de mídia, realizadas a partir de um convênio entre o Núcleo de Estudos em Cultura Midiática e o Centro de Arte e Cultura (CAC) da UFRRJ, para as comunidades do seu entorno. Deste modo, refletimos acerca dos processos de construção e das atividades desenvolvidas neste projeto de extensão, cujo objetivo é elaborar aulas para essas oficinas, com alunos do curso de jornalismo, e depois ministrá-las para cursistas do CAC, durante o período remoto. A leitura crítica de mídia, quando construída coletivamente, estimula reflexões e amplia os repertórios dos sujeitos, tornando-os mais conscientes, atentos e participativos ao papel das mídias. No presente artigo, discutimos sobre o potencial da formulação de leituras em oficinas que desenvolvem um olhar crítico e analítico sobre os conteúdos midiáticos e favorecem a ampliação destes repertórios.
\end{abstract}




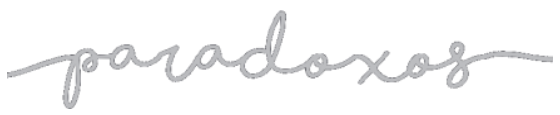

Educação Midiática e referenciais

metodológicos para a elaboração

de oficinas no Ensino remoto

MOREIRA, MORAES, ARAGÃO, PINTO, 2020

Palavras-chave: Educação Midiática. Leitura Crítica de Mídia. Comunicação.

\begin{abstract}
The article debates the elaboration of workshops of critical media reading, performed by a partnership between the Center for Studies in Media Culture and the Center for Art and Culture (CAC) from Rural Federal University of Rio de Janeiro, for the communities of its surroundings. Thus, we reflect about the process of construction and the activities developed in this extension project, whose objective is to prepare classes for these workshops, with journalism students, and then teach them to CAC students, during the remote period. The critical media reading, when built collectively, stimulates reflexions and expands the repertories of the subjects, making them more conscious, attentive and participative to the role of media. In the present article, we argue about the potential of the formulation of readings in workshops that develop a critical and analytical look about the content and favor the amplification of these repertories.
\end{abstract}

Keywords: Media Education. Critical Reading of Media Communication. Communication.

\title{
Resumen
}

El artículo discute la elaboración de los talleres de lecturas críticas mediáticas, realizados a partir de un convenio entre el Centro de Estudios en Cultura Mediática y el Centro de Arte y Cultura (CAC) de la Universidad Federal Rural de Río de Janeiro, para las comunidades de su entorno. Así, reflexionamos sobre los procesos constructivos y actividades desarrolladas en este proyecto de extensión, cuyo objetivo es preparar clases para estos talleres, con alumnos del curso de periodismo, y luego enseñarlas a los alumnos del CAC, en el período de clases remotas. La lectura crítica de los medios, cuando se construye colectivamente, estimula la reflexión y amplía los repertorios de los sujetos, haciéndolos más conscientes, atentos y participativos al papel de los medios. En este artículo, discutimos el potencial de formular lecturas en talleres que desarrollen una visión crítica y analítica del contenido mediático y favorezcan la expansión de estos repertorios.

Palabras clave: Educación Mediática. Lectura Crítica de los Medios de Comunicación. Comunicación.

\section{Introdução}

A educação midiática parte da ideia de educar o olhar para as mídias, aprendendo a questionar e fazendo uma leitura crítica dos conteúdos que são veiculados DOI: http://doi.org/10.14393/par-v6n1-2021-60541 - Paradoxos, Uberlândia, v. 6, n. 1, p. 38-55, jan./jun. 2021| 39 


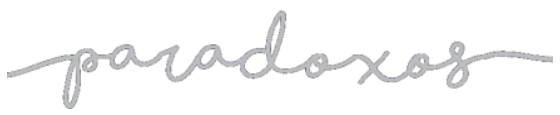

Educação Midiática e referenciais metodológicos para a elaboração de oficinas no Ensino remoto

MOREIRA, MORAES, ARAGÃO, PINTO, 2020

por elas. A relação entre mídia e educação estimula a reflexão dos cidadãos a se apropriarem dos conteúdos e pensarem nas narrativas midiáticas enquanto espaços de construção cultural e social.

Neste artigo, apresentamos a análise de um projeto de Educação Midiática de produção de oficinas para o Centro de Arte e Cultura (CAC), da Universidade Federal Rural do Rio de Janeiro (UFRRJ). O CAC promove atividades artísticas e culturais para a comunidade acadêmica e externa, em particular do entorno de Seropédica-RJ, com o objetivo de ampliar o acesso à cultura de forma livre e gratuita. A oficina de Leituras Críticas de Mídia, com o tema "Cinema e Literatura - a literatura na tela" propõe, a partir de aulas construídas coletivamente, com discentes do curso de Jornalismo, promover novas interpretações e olhares sobre a adaptação da literatura para o cinema. Nosso principal objetivo é promover a construção coletiva de conhecimento a fim de fomentar outras formas de pensar essas narrativas. Incentiva-se o debate das mensagens e temáticas de filmes e livros, por meio de uma metodologia que visa a especificação das aulas, com uma pergunta deflagradora e propostas de leituras críticas. Com a adaptação das aulas para o modelo do ensino remoto, devido à pandemia da Covid-19, foi necessário ainda pensar novas formas e dinâmicas para essas oficinas, principalmente no que diz respeito ao material das aulas, as atividades propostas e a interação com os participantes. O objetivo é debater, neste artigo, de que forma esse saber coletivo foi construído nessas oficinas, a fim de promover discussões e colaborar para a construção de novas formas de fazer educação midiática.

Sendo assim, afirmamos que a mídia é onipresente no cotidiano contemporâneo, por isso é parte fundamental na construção da nossa percepção social. Além de constituir um sistema de informação global, ela contribui para a nossa visão de mundo, sendo considerada, muitas vezes, como meio de educação não formal dos cidadãos. Pedrinho Guareschi e Osvaldo Biz (2005) fazem quatro afirmações sobre o fenômeno dos meios de comunicação que ilustram esse impacto: a comunicação constrói a realidade, isto é, a existência ou não de algo depende de isso ser ou não midiado; a mídia dá conotação valorativa, por isso legitima determinados discursos; a mídia insere a agenda de discussão, ao decidir colocar ou não um tema em pauta, o que interfere nos assuntos discutidos nos 


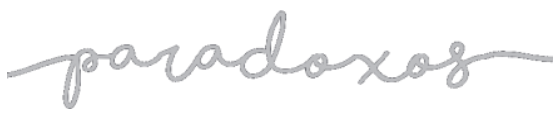

Educação Midiática e referenciais metodológicos para a elaboração de oficinas no Ensino remoto

MOREIRA, MORAES, ARAGÃO, PINTO, 2020

meios sociais; a mídia constrói nossa subjetividade, já que ela seria mais um personagem dentro das casas com quem nos relacionamos diariamente.

Guareschi e Biz (2005) destacam, portanto, o poder da mídia de construir mensagens que impactam, de maneiras diversas, as dinâmicas sociais. Contudo, com frequência, nos questionamos acerca da nossa capacidade de pensá-la criticamente, como sujeitos imersos em uma cultura já midiatizada. Essa questão é de suma importância para os estudos das relações entre mídia e educação. Os termos "mídiaeducação", "leitura crítica de mídia", "media literacy" (letramento midiático), "educomunicação" e "educação midiática" trazem à luz a correlação de forças que constituem modos de pensar tanto o impacto das mídias nas nossas visões de mundo quanto questionar os diversos usos das suas narrativas.

A leitura crítica de mídia inclui práticas como observatórios de mídia e imprensa, que debatem e pensam criticamente sobre o trabalho jornalístico em circulação nos veículos de comunicação. Em educação midiática, há um maior foco na educação para a leitura das mídias, ainda que essa ideia não esteja dissociada da noção de leitura crítica, analítica ou reflexiva. Nesse caso, porém, pode-se pensar mais propriamente nas atividades desenvolvidas em sala de aula, por exemplo. (FANTIN, 2011)

Nesse artigo, abordamos a prática da educação midiática construída coletivamente em oficinas de leituras críticas de mídia no Centro de Arte e Cultura (CAC), da UFRRJ, com a participação dos discentes do curso de Jornalismo nesse processo. Para isso, faz-se necessário delimitar essa área. Roseane Andrelo e Ligia Beatriz Carvalho de Almeida (2015) definem esse campo da seguinte forma:

Educação para a mídia, mídia-educação, educomunicação e media literacy são termos usados para caracterizar uma área interdisciplinar do conhecimento que se preocupa em desenvolver formas de ensinar e aprender aspectos relevantes da inserção dos meios de comunicação na sociedade. Assim, a "literacia em mídia" é o resultado esperado de ações pedagógicas, que envolvem compreensão crítica das mensagens, da função da comunicação e participação ativa na esfera da comunicação social. (ANDRELO; DE ALMEIDA, 2015, p. 51)

Dessa forma, a educação midiática nos possibilita conhecer e nos apropriarmos dos conteúdos propagados pelas mídias, reconhecendo que tipos de representações estão ou não presentes nesses discursos. Além disso, auxilia na busca de discernir que tipos 


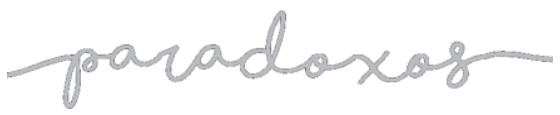

Educação Midiática e referenciais metodológicos para a elaboração de oficinas no Ensino remoto

MOREIRA, MORAES, ARAGÃO, PINTO, 2020

de identificações se tem com o que nos é apresentado, tendo em vista que, na contemporaneidade, esse cenário é potencializado pelos meios digitais.

Se considerarmos a mídia como um espaço de construção de representações e identidades contemporâneas, ela deve ser acessada de modo crítico. É nesse sentido que caminham as reflexões de Beatriz Becker (2016), para quem "a educação deve avançar estimulando a interpretação dos textos midiáticos e a compreensão de que estes não são reflexos da realidade, mas construções que direcionam a criação de vínculos e identidades." (BECKER, 2016, p. 128). Por isso, os estudantes e cidadãos são participantes ativos na construção de sentidos e significados das mensagens dos meios. A educação midiática visa estabelecer, de forma mais propositiva, essas mediações e facilitar a implicação dos atores sociais no processo de leitura crítica.

A mídia-educação está, então, estreitamente associada às noções de democracia e cidadania. Carvalho (apud PINTO, 2012, p. 4) discorre sobre uma mídia a serviço da democracia e não de uma democracia ditada pela mídia. Afirmamos que a educação midiática seja exatamente isso: potencializar nos estudantes o olhar crítico, as interpretações e opiniões próprias, impulsionando uma mídia a serviço da democracia, sujeita não apenas aos emissores das mensagens, mas também ao cidadão que atua fortemente no campo social e negocia ativamente sentidos.

Como apontado por Esther da Costa e Giselle Ferreira dos Santos (2013), historicamente, a mídia-educação se desenvolveu concomitantemente à Indústria Cultural $^{1}$ na Europa. No início do século XX, "as mídias eram vistas como anticulturais e, por isso, eram um mal que a educação deveria combater" (DA COSTA; DOS SANTOS FERREIRA, 2013, p. 148). Nesse contexto, a ideia de leitura crítica da mídia foi impulsionada de fato na década de 60, inclusive com o progresso do cinema (um dos focos das oficinas analisadas neste artigo). Já na

\footnotetext{
${ }^{1}$ Cunhado por Adorno e Horkheimer, o conceito de indústria cultural diz respeito à transformação da cultura em mercadoria. Os autores viam o desenvolvimento tecnológico e a expansão dos meios de comunicação de massa como o lugar da não-cultura, diferentemente da cultura erudita. Esse olhar anticultural e, por vezes, elitista dos meios considera que a reprodução massiva de bens culturais empobrece e padroniza a cultura. Para os pensadores da Escola de Frankfurt a relação com a cultura, a partir principalmente no início do século XX, com o desenvolvimento dos meios de comunicação, se tornou empobrecida e destituída de potência quando esta se transformou em bem de consumo. Adorno e Horkheimer, no célebre texto Indústria Cultural ou o Iluminismo como Mistificação das Massas, afirmam que a relação com cultura torna-se padronizada e serializada quando faz parte de um sistema geral de produtos gerados pelo mercado. O sistema capitalista, neste sentido, gera a falsa ideia de que a cultura é espontânea das próprias massas quando na realidade é vendida para as massas.
}

DOI: http://doi.org/10.14393/par-v6n1-2021-60541 - Paradoxos, Uberlândia, v. 6, n. 1, p. 38-55, jan./jun. $2021 \mid 42$ 


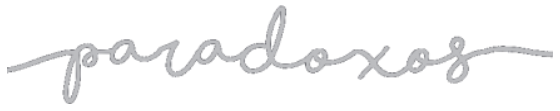

Educação Midiática e referenciais metodológicos para a elaboração de oficinas no Ensino remoto

MOREIRA, MORAES, ARAGÃO, PINTO, 2020

década de 70, é importante destacar o papel da Organização das Nações Unidas para a Educação, a Ciência e a Cultura (UNESCO) nesse debate:

Inicialmente, em 1973, a UNESCO apresentava a escola como único espaço para o desenvolvimento dessa educação. Na década seguinte, no documento Éducation aux médias (UNESCO, 1984), a Organização redefine a concepção da educação para as mídias, enfatizando que ela não está restrita aos espaços escolares, pois "abrange todas as maneiras de estudar, de aprender e de ensinar em todos os níveis [...] e em todas as circunstâncias, a história, a criação, a utilização e a avaliação das mídias". Somada à alfabetização literária, a educação, sob esta ótica, deve promover essa alfabetização para os meios. (DA COSTA; DOS SANTOS FERREIRA, 2013, p. 149).

Atualmente, essa visão monolítica, tributária principalmente da Teoria Crítica ${ }^{2}$, que toma as mídias em seu aspecto anticultural, foi ultrapassada em prol de posicionamentos mais amplos, como os Estudos Culturais ${ }^{3}$, e que conseguem abarcar sua dimensão dinâmica, processual e criativa. Neste sentido, as ideias que permeiam essas análises entendem que a mídia constrói culturas, produz modos de ser e pensar. Estudar criticamente esses processos torna-se fundamental e é estimulado por esse campo interdisciplinar da educação midiática. Assim, acreditamos estar alinhada à nossa proposta a noção de que estudar as mídias não é algo restrito aos ambientes escolares, nem à relação professor-aluno. Quando pensamos em nossa experiência na realização das oficinas de leituras críticas de mídia, no Centro de Arte e Cultura (CAC), traçamos mais claramente essa relação protagonista de exercer as leituras com muitos públicos e fora do ambiente escolar clássico. As oficinas já receberam desde moradores dos bairros e municípios dos arredores de Seropédica, onde se localiza a sede principal da Universidade Federal Rural do Rio de Janeiro, até alunos da rede pública e da própria comunidade universitária.

$\mathrm{Na}$ perspectiva do ensino remoto, as possibilidades se expandem ainda mais, pois esse público não se restringe geograficamente ao ambiente universitário

\footnotetext{
${ }^{2}$ Como explicado por Rüdiger (2001), a Teoria Crítica foi impulsionada pela Escola de Frankfurt, a partir dos anos 40. Refletia sobre a comunicação em relação à sociedade como um todo, levando em conta economia, política, relações sociais e desenvolvimento tecnológico, com o objetivo de fazer crítica aos meios de comunicação de massa. É nesse contexto que surgiu o conceito de indústria cultural, já que essa corrente de pensamento via a mídia por um viés anticultural e pessimista. Ver mais em "Teorias da Comunicação: conceitos, escolas e tendências".

${ }^{3}$ Os Estudos Culturais, a partir dos anos 60, abriram espaço para discussões mais amplas em relação à cultura. Segundo Douglas Kellner (2001), a cultura da mídia é um lugar de produção de significados, mas também de apropriação e resistência, gerando leituras múltiplas e novas manifestações culturais por parte da sociedade.

DOI: http://doi.org/10.14393/par-v6n1-2021-60541 - Paradoxos, Uberlândia, v. 6, n. 1, p. 38-55, jan./jun. $2021 \mid 43$
} 


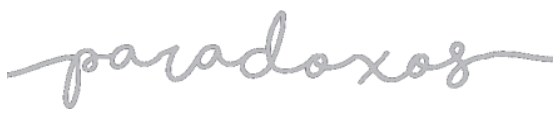

Educação Midiática e referenciais metodológicos para a elaboração de oficinas no Ensino remoto

MOREIRA, MORAES, ARAGÃO, PINTO, 2020

e aos arredores de Seropédica. Contudo, é preciso levar em conta as desigualdades de acesso à internet e às Tecnologias Digitais de Comunicação e Informação (TDCI). Natália Flores e Ana Arent (2020) destacam que os dispositivos mais disponíveis para os brasileiros são os telefones celulares, mas sua distribuição é feita de forma desigual. É preciso considerar ainda que o nível de acesso à internet em residências urbanas é maior que em residências rurais e há contratempos como as dificuldades de conexão e o custo elevado do serviço. Dados do IBGE, de $2017^{4}$, apontam que 25,1\% dos domicílios brasileiros não têm (ou não tinham naquele momento) acesso à internet. Por isso, apesar das novas dinâmicas e possibilidades do ensino remoto, há limites e contratempos nesse processo. Para viabilizar os Estudos Emergenciais em 2020, a UFRRJ adotou medidas de inclusão digital para alunos em vulnerabilidade econômica e alunos com deficiência ${ }^{5}$ como formas de atenuar, em parte, esse problema.

Além disso, com a participação de alunos do curso de Jornalismo na elaboração das aulas que são ministradas nas oficinas, promove-se uma educação midiática posta em prática no coletivo, com propostas de intervenções e atividades em que os cursistas das oficinas possam se expressar e construir conjuntamente. Assim como destacado por Maria Aparecida Pinto (2012): “a educação para os meios deve estabelecer o debate e a construção de um saber e não de uma transmissão unilateral.” (PINTO, 2012, p. 6)

O projeto das oficinas de leituras críticas de mídia, ademais, leva a cabo o propósito de relacionar extensão e pesquisa, tendo em vista que "nos deparamos com múltiplos desafios não previstos apenas com o olhar reflexivo da pesquisa. O fazer nas oficinas impôs de forma mais precisa olhares transversalizados com, para e da mídia." (MOREIRA, 2020, p. 2).

Com o objetivo de entender o potencial da elaboração das aulas das oficinas críticas de mídia, partimos da ideia de que ensinar é também aprender. Nesse sentido, todos os conteúdos e ideias foram forjados coletivamente, a partir de múltiplos repertórios e formas de aprender os temas.

\footnotetext{
${ }^{4}$ Dados da Pesquisa Nacional por Amostra de Domicílios Contínua (PNAD) de 2018. Disponível em: https://biblioteca.ibge.gov.br/visualizacao/livros/liv101631_informativo.pdf. Acesso em: 09 jun. 2021.

5 Essa informação foi divulgada no site oficial da universidade. Disponível em: https://portal.ufrri.br/ufrrj-adota-medidas-para-inclusao-digital-de-alunos-em-vulnerabilidadesocioeconomical. Acesso em: 09 jun. 2021.
}

DOI: http://doi.org/10.14393/par-v6n1-2021-60541 - Paradoxos, Uberlândia, v. 6, n. 1, p. 38-55, jan./jun. 2021| 44 


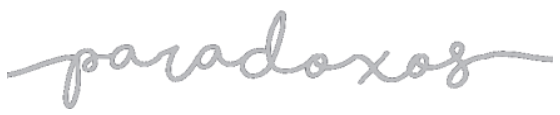

Educação Midiática e referenciais metodológicos para a elaboração de oficinas no Ensino remoto

MOREIRA, MORAES, ARAGÃO, PINTO, 2020

\section{Sobre modos de fazer e pensar em conjunto no sistema remoto}

Com o início das aulas remotas na UFRRJ, o período excepcional foi ofertado e com ele a Atividade Acadêmica (AA) ${ }^{6}$ de Laboratório de Educação Midiática. Os encontros aconteceram com periodicidade de um dia na semana, em 2 horas/aula, a fim de elaborar as aulas para o CAC a serem ministradas no semestre seguinte. Para confecção do trabalho, foi necessário pensar em uma cronologia e organização de aula, além de avaliar o público envolvido. No total, foram 24 discentes matriculados na AA, mais duas bolsistas (BIEXT- PROIC) e uma monitora.

O tema proposto para a produção das aulas foi "Cinema e Literatura - A literatura na tela". Os discentes do curso de Jornalismo, matriculados no Laboratório de Educação Midiática, precisariam escolher um filme que foi inspirado em um livro, cuja apresentação se daria em três tempos: 1) apresentação dos participantes e do tema; 2) historicização e contextualização do objeto a ser estudado e 3) produção de ações práticas para as oficinas. Esses passos mapeariam os processos de elaboração das aulas, de forma a funcionar como uma metodologia de ação, que guiaram as pesquisas dos grupos. Para o primeiro, a pergunta deflagradora ${ }^{7}$ seria o ponto de partida para a discussão. No segundo, uma introdução dentro da história contada por ambas as mídias. Por último, a escolha de uma atividade para instigar o cursista a questionar conteúdos para leitura crítica.

Nosso mapa de produção das aulas foi constituído, assim, com o que denominamos princípios de ação:

\footnotetext{
${ }^{6}$ Essa modalidade de Atividade Acadêmica é prevista na estrutura geral da UFRRJ. O curso de jornalismo oferece múltiplos laboratórios na modalidade AA (laboratórios de TV, Rádio, Digital e Pesquisa) para os alunos que devem, durante seu percurso, cumprir uma carga horária geral de 4 laboratórios.

7 No percurso do projeto de construção das aulas, desenvolvemos a ferramenta das perguntas deflagradoras. Elas deveriam funcionar como ponte entre os conteúdos desenvolvidos no filme, livro ou mídia estudada e as realidades dos sujeitos envolvidos.
}

DOI: http://doi.org/10.14393/par-v6n1-2021-60541 - Paradoxos, Uberlândia, v. 6, n. 1, p. 38-55, jan./jun. 2021| 45 
Quadro 1: Produção e preparação das aulas

\section{Preparacão de Aulas}

As aulas serão apresentadas por cada grupo, toda semana. As datas estão programadas.

Princípios das aulas

Aulas de 3 horas, divididas em 3 atos:

1) Apresentação dos participantes, apresentação do tema e pergunta deflagradora

2) Historicização do filme e livro/objeto/tema

3) Atividade proposta

Aulas com diversas temáticas: racismo, violência, gênero

As aulas deverão ser apresentadas necessariamente em slides e poderão contar com trechos de filmes, trechos dos livros e discussões pautadas em artigos e ideias.

Fonte: Elaborado pela coordenadora do projeto Rejane Moreira.

Nas apresentações, era preciso refletir a mudança de narrativa de cada meio de comunicação. Com os grupos separados, cada um escolheu o tom da temática para seu objeto que, ao trabalhar a transnarrativa ${ }^{8}$ midiática, precisaria abordar, principalmente, as comparações entre o filme e seu respectivo livro, além do conteúdo crítico. Todo o material foi disponibilizado em slide, que funcionava como suporte de apresentação, mas também como elemento mnemônico das discussões pautadas em artigos e ideias. Ademais, uma das questões realizadas durante a apresentação foi como a narrativa muda em cada meio e como o filme vai se adaptar a esse novo diálogo. Inspirados por Serelle (2016), é possível compreender que cada predileção do tema é equivalente ao processo de debate em grupo.

O modo como um indivíduo dedica atenção a um texto, escolhendo-o, interpretando-o e fazendo uso dele, passa, evidentemente, pela questão subjetiva, mas essa própria subjetividade é construída em diálogo com as mediações dos grupos e das classes. (SERELLE, 2016, p. 79).

Foram divididos seis grupos com os seguintes filmes/livros: "Jogos Vorazes"; "Estrelas Além do Tempo"; "Extraordinário"; "O Grande Gatsby”; "O Menino do

\footnotetext{
${ }^{8} \mathrm{O}$ conceito de transnarrativa é equivalente a entrelaçar os meios digitais em ambientes midiáticos e reconhecer os componentes narrativos e sua disseminação por práticas discursivas muito diversas. $\mathrm{O}$ termo foi popularizado, em 1995, pelo autor norte-americano Martin Kreiswirth, no seu artigo "Tell me a story: the narrativist turn in the human sciences".
}

DOI: http://doi.org/10.14393/par-v6n1-2021-60541 - Paradoxos, Uberlândia, v. 6, n. 1, p. 38-55, jan./jun. 2021| 46 


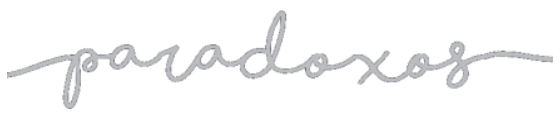

Educação Midiática e referenciais metodológicos para a elaboração de oficinas no Ensino remoto

MOREIRA, MORAES, ARAGÃO, PINTO, 2020

Pijama Listrado"; "Orgulho e Preconceito". Os temas variaram em temática, levando em consideração histórias, respectivamente, sobre controle de poder e opressão, raça e gênero, bullying e preconceito velado, sonho americano e desigualdades sociais, nazismo e segregação e, por último, machismo. Os grupos tiveram tempo para montar suas apresentações em conjunto com a produção de um material final, para que o próximo bolsista do projeto utilizasse durante a ministração das aulas na oficina.

Embora na confecção de outras oficinas ${ }^{9}$ a pergunta deflagradora tenha aparecido no início das apresentações, desta vez os grupos decidiram fazer diferente. Em uma decisão coletiva espontânea, as indagações ficaram para a parte final da apresentação, com intenção de questionar criticamente os cursistas e implementar a proposta da atividade. Durante as apresentações, era possível tirar dúvidas, questionar e sugerir novas ideias a fim de melhorar o produto final, além de todas as observações e pedidos de mudança da docente coordenadora, que também conduziu os processos de ensino e aprendizado.

O esquema de aula para oficina com o tema "Cinema e Literatura - A literatura na tela" foi reelaborado pelas bolsistas e também pela monitora do Laboratório de Educação Midiática. Nesse processo, era importante compreender que ler criticamente é entender como se faz. No trabalho em grupo, confeccionado pelos alunos matriculados no Laboratório, foi instituída a produção de uma aula com início, meio e fim, direcionada, principalmente, ao público participante do CAC. Ao apresentar a obra e sua adaptação cinematográfica na apresentação de slides, era preciso considerar as seguintes questões: "Como o cinema se espelha na literatura para construir uma narrativa própria dele mesmo?”; “Qual a temática da obra?”; “O que pode ser tratado para pensar a história de forma mais profunda, mais crítica?”; "Quais estratégias usar para que o cursista leia, perceba e entenda o livro/filme?"; "Quais atividades serão propostas para trabalhar essa obra em uma aula da oficina?".

Para isso, era preciso considerar também os aspectos históricos, midiáticos e narrativos que ambas as mídias (livro e filme) ofereceram ao público, visto que, por exemplo, alguns títulos foram planejados para serem trilogias e, no cinema, foram adaptados para quatro filmes. Além disso, durante a montagem da apresentação, foi preciso fazer pequenos recortes do filme e do livro e procurar embasamento crítico em

\footnotetext{
9 Antes dessa oficina realizamos outras duas, cujos temas foram: Fanzines e a Construção do herói (2019) e Audiovisual e Representação (2020). 


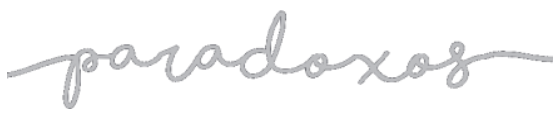

Educação Midiática e referenciais metodológicos para a elaboração de oficinas no Ensino remoto

MOREIRA, MORAES, ARAGÃO, PINTO, 2020

artigos científicos, monografias, matérias jornalísticas e outros, para formar as diretrizes da aula, como as atividades ao final da oficina.

Com os encontros, elaboramos as aulas e delineamos coletivamente, a partir da pergunta deflagradora, propostas de leituras críticas. Com o grupo de trabalho na Atividade Acadêmica (AA) de Laboratório de Educação Midiática, a ideia era deixar indicadas as temáticas e os conteúdos para serem ministrados pelo bolsistaoficineiro no semestre seguinte, no entanto, todo devido cuidado foi tomado no sentido de não engessar possíveis outras leituras. O projeto consistia em deixar pistas e caminhos de análises e não impor um olhar acerca da crítica. Guiar o que foi refletido, despertar a curiosidade dos cursistas com relação àquela mídia e não impedir novas visões e críticas. A metodologia de ação, seguindo os três tempos de apresentação, foi justamente um recurso de como fazer a oficina impulsionar outras leituras e acrescentar, àquelas já indicadas, nuances vindas de outros repertórios. Para Barbosa e Clementino (2009),

Neste contexto, ganha importância o trabalho em equipe, como um momento para consulta, diálogo e colaboração. Atuando como "colaboradores", alunos e professores experimentam, buscam caminhos e alternativas possíveis, dialogam e trocam informações e conhecimentos, criando um novo ambiente de ensino em que ambos aprendem. (BARBOSA; CLEMENTINO, 2009, p. 2).

O desenvolvimento de um trabalho em grupo de forma remota era uma novidade e não era totalmente dominado. Por isso, foi realizada uma pesquisa após o término da atividade do Laboratório, através de um formulário on-line, com algumas perguntas sobre como foi fazer um trabalho em grupo remotamente. As perguntas foram: "1) Você gostou de produzir esse trabalho? 2) Qual foi a maior diferença entre produzir um trabalho de forma on-line e presencialmente? 3) A produção do trabalho foi dificultosa, principalmente por ser on-line? 4) O trabalho ser em grupo foi um problema para você, nesse período remoto? 5) Você acha que produziria esse trabalho mais facilmente se fosse presencial? 6) Você enfrentou algum problema técnico ao tentar produzir esse trabalho ou frequentar as aulas? 7) Se a sua última resposta foi sim, quer nos contar um pouco sobre o que aconteceu?". A partir das respostas, avaliamos como a produção de um trabalho no modo remoto foi feito, com a manutenção do tempo, da reflexão e da colaboração para produzir o todo.

DOI: http://doi.org/10.14393/par-v6n1-2021-60541 - Paradoxos, Uberlândia, v. 6, n. 1, p. 38-55, jan./jun. $2021 \mid 48$ 


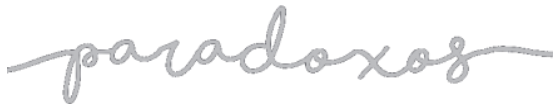

Educação Midiática e referenciais metodológicos para a elaboração de oficinas no Ensino remoto

MOREIRA, MORAES, ARAGÃO, PINTO, 2020

Para aqueles que responderam ao formulário, as maiores diferenças entre produzir um trabalho remotamente e presencialmente foram a falta de contato com os colegas de classe e a divergência de disponibilidade para os encontros on-line. Adicionado a isso, o momento pelo qual estamos passando - pandemia do Covid-19 e quarentena - afetou o emocional dos alunos e desmotivou, em muitos momentos, a realização da atividade.

De 8 pessoas que responderam, 6 disseram que o trabalho ser em grupo no período remoto não foi um problema e 7 que seria mais fácil produzi-lo presencialmente. Sobre problemas técnicos, 5 responderam que, durante a aula ou até mesmo durante a apresentação dos slides, a falta de boa conexão de internet e de qualidade dos equipamentos eletrônicos prejudicou a interação e o acompanhamento de todas as aulas. Além disso, a dupla jornada durante a pandemia, com trabalho e estudo ao mesmo tempo, também afetou a concentração e a dedicação desses estudantes.

No mais, apesar de terem encontrado alguns problemas, os trabalhos foram feitos e apresentados de forma única e bem delineada. Todos os grupos se empenharam em produzir um conteúdo crítico e analítico das mídias que, para Barbosa e Clementino (2009), faz com que além de ensinar, a educação on-line envolva as pessoas e as faça colaborar em equipe de forma organizada e harmônica. Dessa forma, explicaremos a seguir como a construção do coletivo nos faz analisar as mídias de outra forma, além daquelas que já havíamos nos habituado.

\section{Quando pensar coletivamente forja um outro olhar para as mídias}

O Centro de Arte e Cultura (CAC), da Universidade Federal Rural do Rio de Janeiro (UFRRJ), desde sua inauguração, em 2007, transformou-se em um espaço que acolhe, de forma propositiva, as demandas artísticas e culturais presentes das cidades que sediam os campi da UFRRJ, a saber, Seropédica, Nova Iguaçu e Três Rios. O CAC oferece uma média de 30 oficinas ministradas pelos próprios alunos, que colocam em prática aquilo que aprendem dentro e fora da universidade. Nesse espaço, os alunos oferecem oficinas como pintura, teatro, dança, desenho, entre outras. O público que 


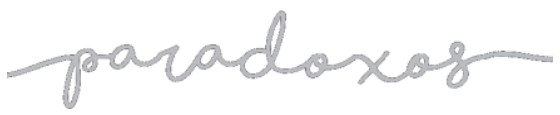

Educação Midiática e referenciais metodológicos para a elaboração de oficinas no Ensino remoto

MOREIRA, MORAES, ARAGÃO, PINTO, 2020

circula pelo CAC é diverso, por isso nossa preocupação em produzir oficinas que abraçassem esses comunitários.

As oficinas de Leitura Crítica de Mídia foram também desenhadas para abarcar essa demanda. No processo do ensino e da aprendizagem, as oficinas se apresentaram como possibilidades efetivas de criação de ambientes democráticos e espaços de convergências entre os moradores de Seropédica e os discentes e docentes da universidade.

Dentro do contexto da suspensão das aulas por conta da pandemia de Covid-19, as oficinas do CAC passaram a ser ministradas on-line, algumas de forma assíncrona a partir das redes sociais e outras através de encontros síncronos. Com o uso integral das tecnologias digitais, a aprendizagem passa a se organizar com um caráter mais comunitário, para Vani Moreira Kenski (2003):

A aprendizagem não precisa ser mais apenas um processo solitário de aquisição e domínio de conhecimentos. Ela pode se dar de forma coletiva e integrada, articulando informações e pessoas que estão em locais diferentes e que são de idade, sexo, condições físicas, áreas e níveis diferenciados de formação. (KENSKI, 2003, p. 6).

A mudança que ocorreu em 2020 transpõe as oficinas para o ensino remoto, o que, como já mencionado, possibilita uma expansão do público. Se antes contávamos com a inscrição de alunos da UFRRJ e moradores de Seropédica e seu entorno, nesse formato contamos com alunos de outras instituições e pessoas que residem em áreas afastadas do campus. Essa transição permitiu uma mudança na metodologia, que agora está adaptada para o meio digital. Os materiais de apoio para cada aula são disponibilizados em uma pasta do Google Drive e os debates ocorrem de forma horizontal, todos os alunos têm espaço para emitir opiniões com a tutela das bolsistas. Além disso, o WhatsApp funciona como um espaço importante para a continuidade das discussões. Ao longo da semana, vários alu nos contribuem com novos materiais e informações que ajudam a fundamentar os assuntos discutidos. O processo de construção dialógica e mais ativo com os cursistas nos fez perceber o quão importante é a horizontalização do ensino. Todos se sentem partícipes do processo quando a fala $\mathrm{e}$ as interpretações são coletivizadas no grupo. Minimizar o papel do professor como único detentor do conteúdo e centralizador do ensino é uma experiência nova e foi muito importante 


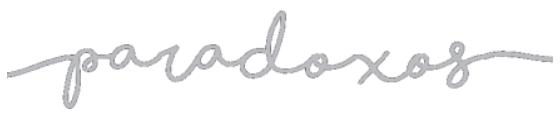

Educação Midiática e referenciais metodológicos para a elaboração de oficinas no Ensino remoto

MOREIRA, MORAES, ARAGÃO, PINTO, 2020

para que os alunos pudessem expressar de forma mais participativa seus repertórios e posicionamentos. Nesse contexto,

Uma das questões trazidas à luz pelos educadores nos últimos anos diz respeito ao fato de a palavra estar centralizada no professor, ficando o aluno na condição de expectante. Caso típico de monólogo que, muitas vezes, insinua promover diálogo. Para muitos, as tecnologias digitais permitiriam romper tal ciclo, pois são vocacionadas à dispersão discursiva e à viabilidade de muitos pronunciamentos se cruzarem, permitindo ampliação democrática e rompendo com o circuito monólogo. (CITELLI; SOARES; LOPES, 2019, p. 16)

Como citado acima, as tecnologias digitais têm grande potencial como auxiliares nas discussões, a oficina on-line prova isso com a expansão de seu público e a maior facilidade na realização de debates e compartilhamento de materiais assíncronos. Nesse sistema, também, muitos cursistas se sentiram mais confortáveis, emitindo suas opiniões e compartilhando diversos questionamentos pelo WhatsApp ou no chat dos encontros síncronos.

A transformação do ambiente físico para o virtual, porém, tem suas limitações. Conseguimos averiguar isso nas diversas demandas dos cursistas com relação ao processo produtivo quando estes estão desenvolvendo algumas atividades de forma isolada. A relação com o meio digital é solitária e muitas vezes instrucional, o que acaba gerando certa fadiga na hora de aprender conteúdos. Neste sentido, a relação com o ambiente digital abre brechas para a ampliação dos públicos, mas exige proatividade, compromisso e certo engajamento diferenciado tanto para bolsistas-tutores, que ministram as oficinas, quanto para os cursistas inscritos nas oficinas. Para os cursistas, é necessário que haja comprometimento e, aos bolsistas responsáveis, cabe a função de incentivadores e moderadores. Como nos indicam os autores,

A educação em rede, pela sua natureza, é um processo que requer o envolvimento profundo dos diferentes atores que nela participam, quer na definição dos objetivos e percursos de aprendizagem da comunidade, quer também nas relações de proximidade construídas nas colaborações entre pares que sustentam os processos de inovação e criação do novo conhecimento. (MOREIRA, HENRIQUES; BARROS, 2020, p. 355)

Portanto, em todos os processos relacionados à produção e ministração das oficinas, o engajamento dos participantes foi muito importante. O incentivo para tal 


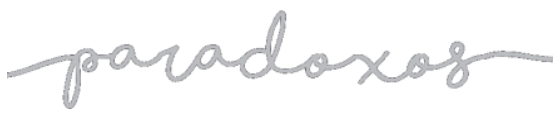

Educação Midiática e referenciais metodológicos para a elaboração de oficinas no Ensino remoto

MOREIRA, MORAES, ARAGÃO, PINTO, 2020

comprometimento desenrolou-se a partir do apoio entre bolsistas e cursistas da oficina, os quais estavam constantemente se estimulando para uma melhor performance.

\section{Considerações finais}

O que podemos apreender dessa experiência em curso de realização é a experimentação constante de um processo de elaboração e ministração das oficinas de forma horizontalizada e dialógica. Na formação do grupo das oficinas buscamos trabalhar esse comprometimento e essa implicação de forma constante. As oficinas favorecem, acima de tudo, a construção coletiva de temáticas e, com o aporte nas mídias digitais no ensino remoto, vimos expandir as possibilidades de diálogos e reflexões com os assuntos sugeridos. Para sustentar certa atitude ética e pedagógica, estabelecemos alguns princípios em que o fazer coletivo seria fundamental para proporcionar novas possibilidades de encontro. Assim, ao longo das preparações das oficinas, nos debruçamos em princípios que colocam o fazer, pensar e agir no mesmo plano. Desse modo, era importante sair de um modelo de organização hierárquico e vertical e buscar arejar as relações entre os membros da pesquisa. As oficinas pautaram-se ainda no princípio da indissociabilidade entre pesquisa-ensino-extensão, no qual a participação de alunos de graduação era imprescindível. A um só tempo, oferecíamos orientação pedagógica e métodos para viabilizar as oficinas de leituras críticas de mídia.

Como nos indica Alvarez (2019):

A escola tradicional e seus processos de ensino e aprendizado costumam se fundamentarem relações dicotômicas, que envolvem antagonismos e disputas de poder. Tais dicotomias, organizadas e gestadas de modo vertical, acabam operando múltiplas separações. Essas dicotomias empreendem divisões entre "quem" ensina e "quem" aprende, entre professor e aluno, entre quem pesquisa e o que é pesquisado (sujeito e objeto), entre escola e comunidade, entre saber acadêmico e saber local, o formal e o informal, a oralidade e a escrita. Tal posição epistemológica se estabelece num processo de objetivação do outro, que excluído dos procedimentos de decisões e escolhas, acaba por se submeter àqueles que "dominam" os espaços de ensino de modo unilateral. Esse modo de ensinar e aprender é sustentado em atitudes de dominação e alienação do outro, tratando-o como ser sem luz. (ALVAREZ, 2019, p. 4) 


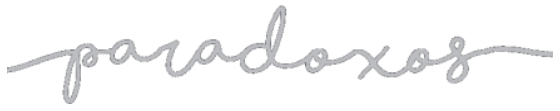

Educação Midiática e referenciais metodológicos para a elaboração de oficinas no Ensino remoto

MOREIRA, MORAES, ARAGÃO, PINTO, 2020

Inspirados nessa proposição, de escapar das dicotomias e não objetificar o conhecimento, realizamos as oficinas em espaços mais arejados e propícios a esses encontros horizontalizados. Neste sentido, consideramos a experiência muito afirmativa, pois a proposta de ler criticamente é também uma proposta de ler com e a partir de repertórios próprios, que podem entrar em consensos provisórios com outros repertórios e forjar espaços mais democráticos.

\section{Referências bibliográficas}

ALVAREZ, Johnny. O ser coletivo então totalitário: experiência em Etnoeducação Quilombolas de Oriximiná P/A. In: Amazônia Latitude, São Paulo, 2019. Disponível em: https://amazonialatitude.com/2019/10/09/o-ser-coletivo-nao-totalitario-uma-experiencia-emetnoeducacao-com-quilombolas-de-oriximina-pal. Acesso em: 08 abr. 2021.

ANDRELO, Roseane; DE ALMEIDA, Ligia Beatriz Carvalho. A mídia e a representação do corpo: leitura crítica dos meios de comunicação. Comunicação Mídia e Consumo, São Paulo, v. 12, n. 34, maio/agosto, 2015. Disponível em:

http://revistacmc.espm.br/index.php/revistacmc/article/view/797/pdf 66. Acesso em: 08 abr. 2021. DOI: https://doi.org/10.18568/1983-7070.123446-66.

BARBOSA, Ana Cristina Lima Santos; CLEMENTINO, Adriana. Trabalhos em Grupo no Ensino Online, maio, 2009. Disponível em: http://www.abed.org.br/congresso2009/CD/trabalhos/1552009125528.pdf. Acesso em: 03 abr. 2021. DOI: https://doi.org/10.5216/ia.v34i1.6557.

BECKER, Beatriz. Mídia, telejornalismo e educação. MATRIZes, São Paulo, v. 10, n. 1, jan/abr, 2016. Disponível em:

https://www.revistas.usp.br/matrizes/article/download/119541/116878/221592. Acesso em: 08 abr. 2021. DOI: https://doi.org/10.11606/issn.1982-8160.v10i1p149-164.

BRAGA, José Luiz. A sociedade enfrenta a mídia: dispositivos sociais de crítica midiática. São Paulo: Ed. Paulus, 2006.

CITELLI, Adilson; SOARES, Ismar de Oliveira; LOPES, Maria Immacolata Vassalho. Educomunicação: referências para uma construção metodológica. Comunicação \& Educação, São Paulo, ano XXIV, n. 2, julho/dezembro, 2019. Disponível em: https://www.revistas.usp.br/comueduc/article/view/165330/159511. Acesso em 01 abr. 2021.

DA COSTA, Esther Silva; DOS SANTOS, Gisele Martins Ferreira. Mídias na Educação: reflexões em torno da apropriação instrumental e leitura crítica das mídias.

Revista Eletrônica do Programa de Pós-Graduação em Mídia e Cotidiano da UFF, Niterói, v. 1, n. 1, janeiro/abril, 2013. Disponível em: https://periodicos.uff.br/midiaecotidiano/article/view/9677/6797. Acesso em 08 abr. 2021. DOI: https://doi.org/10.22409/ppgmc.v1i1.9677. 


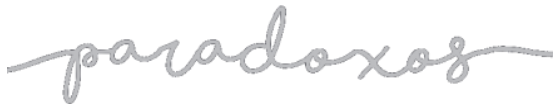

Educação Midiática e referenciais metodológicos para a elaboração de oficinas no Ensino remoto

MOREIRA, MORAES, ARAGÃO, PINTO, 2020

FANTIN, Monica. Mídia-educação: aspectos históricos e teórico-metodológicos. Olhar de Professor, Ponta Grossa, v. 14, n. 1, 2011. Disponível em:

https://revistas2.uepg.br/index.php/olhardeprofessor/article/view/3483/2501. Acesso em: 14 abr. 2021. DOI: https://doi.org/10.5212/olharprofr.v.14i1.0002.

FLORES, Natália; ARNT, Ana. Desigualdade social e tecnologia: o ensino remoto serve para quem?. In: Blogs de Ciências da Unicamp: Especial Covid-19, São Paulo, 2020. Disponível em: https://www.blogs.unicamp.br/covid-19/desigualdade-social-etecnologia-o-ensino-remoto-serve-para-quem/. Acesso em: 08 abr. 2021.

FREIRE, Paulo. Pedagogia da Autonomia: saberes necessários à prática educativa. São Paulo: Paz e Terra, 1994.

GUARESCHI, Pedrinho A.; BIZ, Osvaldo. Mídia, Educação e Cidadania: tudo o que você deve saber sobre mídia. Petrópolis, RJ: Ed. Vozes, 2005.

HOHLFELDT, Antonio; MARTINO, Luiz C.; FRANÇA, Vera Veiga (org.). Teorias da Comunicação: conceitos, escolas e tendências. Petrópolis: Editora Vozes, 2001.

KELLNER, Douglas. A cultura da mídia - estudos culturais: identidade e política entre o moderno e o pós-moderno. São Paulo: EDUSC, 2001.

KENSKI, Vani Moreira. Aprendizagem mediada pela tecnologia. Revista Diálogo Educacional, Paraná, v. 4, n. 10, setembro/dezembro, 2003. Disponível em: https://periodicos.pucpr.br/index.php/dialogoeducacional/article/view/6419. Acesso em: 03 abr. 2021. DOI: https://doi.org/10.7213/rde.v4i10.6419.

MORAN, José Manuel. A educação que desejamos: novos desafios e como chegar lá. 2. ed. Campinas, SP: Papirus, 2007.

MOREIRA, José António Marques; HENRIQUES, Susana; BARROS, Daniela. Transitando de um ensino remoto emergencial para uma educação digital em rede, em tempos de pandemia. Dialogia, São Paulo, n. 34, janeiro/abril, 2020. Disponível em: https://periodicos.uninove.br/dialogia/article/view/17123/8228. Acesso em: 03 abr. 2021. DOI: https://doi.org/10.5585/dialogia.n34.17123.

MOREIRA, Rejane; MACIEL, Sonia. Cadernos de Estudos em Etnoeducação, v. 2. Niterói, RJ UFF/UFRRJ, 2017. Disponível em: https://oriximinablog.files.wordpress.com/2016/06/caderno-de-estudos-emetnoeducac3a7c3a3o-vol-2-final.pdf. Acesso em: 14 abr. 2021.

MOREIRA, Rejane. A Comunicação como Pontes para o Comum e o Encontro: Experiências de Leituras Críticas de Mídia nas Oficinas do CAC-UFRRJ. In: $43^{\circ}$ Congresso Brasileiro de Ciências da Comunicação, 2020, virtual. Anais eletrônicos Intercom - Sociedade Brasileira de Estudos Interdisciplinares da Comunicação. Disponível em: http://www.intercom.org.br/sis/eventos/2020/resumos/R15-0087-1.pdf. Acesso em: 14 abr. 2021. 


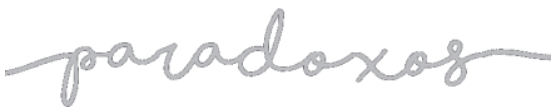

Educação Midiática e referenciais metodológicos para a elaboração de oficinas no Ensino remoto

MOREIRA, MORAES, ARAGÃO, PINTO, 2020

PINTO, Maria Aparecida. Educação para os meios: uma leitura crítica da mídia. In: XVII Congresso de Ciências da Comunicação na Região Sudeste, 2012, Ouro Preto. Intercom - Sociedade Brasileira de Estudos Interdisciplinares da Comunicação. Anais eletrônicos Intercom - Sociedade Brasileira de Estudos Interdisciplinares da Comunicação. Disponível em: http://www.intercom.org.br/PAPERS/REGIONAIS/SUDESTE2012/resumos/R330035-1.pdf. Acesso em: 03 nov. 2020.

RUSSI, Adriana; ALVAREZ, Johnny; MACIEL, Sonia. Cadernos de Cultura e Educação para o Patrimônio, v. 3. Niterói, RJ: s.n. 2014. Disponível em: https://oriximinablog.files.wordpress.com/2016/06/cadernos-de-cultura-vol-3.pdf. Acesso em: 14 abr. 2021.

SERELLE, Marcio. A ética da mediação: aspectos da crítica da mídia em Roger Silverstone. MATRIZes, São Paulo, v. 10, n. 2, maio/agosto, 2016. Disponível em: https://www.revistas.usp.br/matrizes/article/view/119986/117262. Acesso em: 14 abr. 2021. DOI: https://doi.org/10.11606/issn.1982-8160.v10i2p75-90.

SILVA, Gislene; SOARES, Rosana de Lima. Para pensar a crítica de mídias. Revista Famecos, Porto Alegre, v. 20, n. 3, setembro/dezembro, 2013. Disponível em: https://revistaseletronicas.pucrs.br/ojs/index.php/revistafamecos/article/view/14644/107 97. Acesso em: 14 abr. 2021. DOI: https://doi.org/10.15448/1980-3729.2013.3.14644.

SILVERSTONE, Roger. Por que estudar as mídias? São Paulo: Ed. Loyola, 1999.

SOARES, Rosana de Lima; DA SILVA, Gislene. Lugares da crítica na cultura midiática. Comunicação, Mídia e Consumo, São Paulo, v. 13, n. 37, maio/agosto, 2016. Disponível em:

http://revistacmc.espm.br/index.php/revistacmc/article/view/1140/pdf. Acesso em: 08 abr. 2021. DOI: https://doi.org/10.18568/1983-7070.13379-28. 